\title{
Price resolution in an emerging market: Evidence from the Istanbul Stock Exchange
}

\section{G. Geoffrey Booth \& Aydin Yüksel}

To cite this article: G. Geoffrey Booth \& Aydin Yüksel (2006) Price resolution in an emerging market: Evidence from the Istanbul Stock Exchange, The European Journal of Finance, 12:2, 137-152, DOI: $10.1080 / 13518470500146017$

To link to this article: https://doi.org/10.1080/13518470500146017

曲 Published online: 17 Feb 2007.

Submit your article to this journal $\pi$

Џll Article views: 62

Citing articles: 4 View citing articles $\widetilde{ }$ 


\title{
Price Resolution in an Emerging Market: Evidence from the Istanbul Stock Exchange
}

\author{
G. GEOFFREY BOOTH* \& AYDIN YÜKSEL** \\ *Eli Broad Graduate School of Management, Michigan State University, East Lansing, USA, ** Faculty of Business \\ Administration, Bilkent University, Ankara, Turkey
}

\begin{abstract}
This study examines price resolution an emerging market that uses a very large relative tick size. Intraday transaction data from the Istanbul Stock Exchange are used to provide evidence concerning clustering when prices change and when they do not change. The results show that in this one-tick market there exists little if any clustering. The clustering that does exist primarily arises from sequential transactions at the same price. The observed positive relation between clustering associated with price changes and uncertainty occurs in periods of high uncertainty during which multiple-tick spreads and price changes are observed.
\end{abstract}

KEY WORDS: Stock price clustering, tick size, emerging markets, Istanbul Stock Exchange

\section{Introduction}

Modern stock markets are characterized by rules and regulations designed to promote orderly and efficient trading. One important design characteristic is tick size. A tick is the minimum price change allowed, and it determines the set of feasible discrete trading prices. As Angel (1997) points out, the mandated tick rules vary considerably among world's equity markets, although the relative tick sizes (the ratio of tick size to price) are typically similar. One of the phenomena related to price discreteness is the so-called price-clustering anomaly. Clustering occurs when the last digit of prices tend to congregate at round or even numbers. For example, as Harris (1991) mentions, integers are observed more often than halves, halves more than quarters and quarters more than eighths.

The widely accepted explanation of clustering relies on the inability of traders to determine the true price of the stock at the time of the trade. Ball et al. (1985) and Harris (1991) label this explanation the price resolution hypothesis. In this view, clustering occurs when traders, realizing that prices are fuzzy, adopt a coarser set of prices than the set dictated by the tick size. Harris (1991) posits that the choice of the coarser prices is the result of the tradeoff between lower negotiation costs on one hand and higher gains from trade on the other. Grossman et al. (1997) assert that it is not surprising that coarser prices are often used because a properly designed tick rule should be able to accommodate the infrequent times that a high degree of precision is needed.

Correspondence Address: G. Geoffrey Booth, Department of Finance, Eli Broad Graduate School of Management, Michigan State University, East Lansing, MI 48824, USA. Email: boothg@pilot.msu.edu 
Price clustering has been documented in the literature at varying amounts in all of the stock markets that have been examined to date. The vast majority of the empirical evidence supporting the notion that clustering has become a stock market stylized fact comes from developed markets. Hameed and Terry (1998) and Brown et al. (2002), however, collectively offer some supportive evidence from several Asian emerging markets. The purpose of this paper is to question the contention that clustering is a stylized fact and suggest that the phenomenon is a result of tick size. This is accomplished by analysing the Istanbul Stock Exchange (ISE), which has comparatively very large relative tick sizes.

Little, if any, economically meaningful clustering characterizes the ISE. The clustering that is observed is associated primarily with price stickiness, i.e. sequential transactions at the same price. In addition, bid-ask spreads and transaction price changes are typically only one tick. ${ }^{1}$ The high frequency of these one-tick price changes appears to be the reason for the existence of limited amount of clustering associated with price changes. There is some evidence that when prices change by more than one tick, some clustering of this kind occurs. The limited amount of clustering in the ISE can be partially explained by the price resolution hypothesis. These findings support the notion that clustering is not a stylized fact. In addition, they also indicate that the ISE tick may be too large to permit traders to achieve the needed precision in their price setting.

The remainder of the paper is organized as follows. The next section introduces the ISE and presents the data. The third section measures the extent of clustering and juxtaposes it to the distributions of price changes and spreads. The fourth section analyses how these three variables vary with the uncertainty about underlying security values in the market. The last section provides concluding remarks.

\section{Data and Environment}

Founded in December 1985 and fully automated by October 1994, the ISE is a continuous auction market that matches buy and sell orders on a price and time priority basis. Typically, trading is conducted in morning and afternoon sessions. These sessions are separated by a two-hour break that begins at noon. Price changes are governed by price limits and by the tick sizes mandated by exchange rules. Both depend on the volume-weighted average price (WAP) in the previous session. $^{2}$ In any particular session, a transaction price cannot exceed plus or minus $10 \%$ of the relevant WAP (after rounding to the nearest feasible trading price.)

The tick size, which is a step function of WAP, is constructed so that the relative tick size is not materially affected by the share price over a wide range of prices. The ISE has 10 steps or regimes, with each regime being characterized by a different mandated tick size. Details concerning the ISE tick size scheme are presented in Table 1. The first two data columns provide the beginning and ending price of each regime and the third column gives mandated tick size. The final three columns report the relative tick size for each regime's beginning, midpoint and ending price. The mandated tick sizes are structured so that the ending price of every tick regime is associated with a relative tick size of $1.00 \%$. With the exception of the initial tick regime, the regimes begin with a relative tick size of $1.96 \%$ or $2.42 \%$, making the median relative tick size either $1.32 \%$ or $1.42 \%$.

Clustering is examined using transactions data (transaction number, time, session, day, price and volume) provided by the ISE for ISE30 index stocks from January 1998 through February 1999. ${ }^{3}$ Because of changes in the index composition during the 14-month period, 28 stocks with complete data for the sample period are used in the analyses. This time span contains 283 trading days and 564 trading sessions during which more than 8,000,000 transactions occurred for the 
Table 1. ISE tick size scheme

\begin{tabular}{rrrrrrr}
\hline & & & & \multicolumn{3}{c}{ Relative tick size (\%) } \\
\cline { 5 - 6 } Regime & $\begin{array}{c}\text { Beginning } \\
\text { price (TL) }\end{array}$ & $\begin{array}{c}\text { Ending } \\
\text { price (TL) }\end{array}$ & $\begin{array}{c}\text { Mandated } \\
\text { tick } \\
\text { size (TL) }\end{array}$ & $\begin{array}{c}\text { Beginning } \\
\text { price }\end{array}$ & $\begin{array}{c}\text { Midpoint } \\
\text { price }\end{array}$ & $\begin{array}{c}\text { Ending } \\
\text { price }\end{array}$ \\
\hline 1 & 10 & 1,000 & 10 & 100.00 & 1.98 & 1.00 \\
2 & 1,025 & 2,500 & 25 & 2.44 & 1.42 & 1.00 \\
3 & 2,550 & 5,000 & 50 & 1.96 & 1.32 & 1.00 \\
4 & 5,100 & 10,000 & 100 & 1.96 & 1.32 & 1.00 \\
5 & 10,250 & 25,000 & 250 & 2.44 & 1.42 & 1.00 \\
6 & 25,500 & 50,000 & 500 & 1.96 & 1.32 & 1.00 \\
7 & 51,000 & 100,000 & 1,000 & 1.96 & 1.32 & 1.00 \\
8 & 102,500 & 250,000 & 2,500 & 2.44 & 1.42 & 1.00 \\
9 & 255,000 & 500,000 & 5,000 & 1.96 & 1.32 & 1.00 \\
10 & 510,000 & & 10,000 & 1.96 & & \\
\hline
\end{tabular}

Note: TL denotes Turkish lira.

28 stocks combined. In terms of volume, the ISE30 stocks accounted for approximately $70 \%$ of the trading activity.

When compared to other markets, the ISE relative tick size is unusually large. To illustrate this point, consider the tick size rules for the 17 emerging markets, which are regularly followed by the Economist and employ some sort of function that uses at least three steps. The upper part of Table 2 lists these stock exchanges and presents the number of regimes that currently define each market and the comparative relative tick size information. The relative tick size pertains to the median regime and is calculated using this regime's mandated tick size and midpoint price. As shown in the table, the ISE's median relative tick size is substantially larger than the corresponding measure of any of the comparison emerging markets. By way of comparison, the lower part of Table 2 lists three major developed markets that also use step function tick rules. These three markets have a tick environment that is similar to that of the lower ranked emerging markets.

\section{Extent of Clustering in the ISE}

Using different measures, this section presents the extent of clustering in the ISE followed by a comparison to other emerging markets. Since the size of the ISE tick is likely to affect the distribution of price changes, the analysis differentiates between clustering when prices change and when they do not.

Table 3 reports the incidence of clustering in the ISE using the frequencies of the final digits of prices. The ISE's 10 tick regimes are collapsed into three groups or families based on mandated tick size: (1) regimes 10, 100, 1,000, and 10,000, (2) regimes 25, 250, and 2,500, (3) regimes 50, 500 , and 5,000. In each family, the tick size increases from the smallest to the largest tick by a factor of 10. The frequencies for the three families are analysed in two ways. First, for each family the standardized range, which is the difference between the highest and lowest frequencies divided by the expected frequency per unit, is calculated. As pointed out by Grossman et al. (1997), this ordinal measure can be used to rank the degree of clustering present in different markets. Second, the frequencies of transactions with the final digits of zero and five and even (as opposed to odd) final digits are provided. These two categorizations are often used to measure the incidence of clustering. 
Table 2. International market tick size and regime comparisons

\begin{tabular}{|c|c|c|c|c|c|}
\hline \multirow[b]{2}{*}{ Stock Exchange } & \multirow[b]{2}{*}{ Country } & \multicolumn{2}{|c|}{ Tick regimes } & \multicolumn{2}{|c|}{$\begin{array}{l}\text { Relative tick size (\%) } \\
\text { (using midpoint price) }\end{array}$} \\
\hline & & Number & Rank & Median & Rank \\
\hline \multicolumn{6}{|l|}{ Emerging Markets } \\
\hline Istanbul (ISE) & Turkey & 10 & 2 & 1.37 & 1 \\
\hline Philippine & Philippines & 13 & 1 & 1.12 & 2 \\
\hline Jakarta & Indonesia & 3 & 15 & 0.91 & 3 \\
\hline Kuala Lumpur & Malaysia & 7 & 6 & 0.67 & 4 \\
\hline Thailand & Thailand & 10 & 2 & 0.67 & 4 \\
\hline Hong Kong & Hong Kong & 8 & 5 & 0.50 & 6 \\
\hline Singapore & Singapore & 5 & 9 & 0.50 & 6 \\
\hline Taiwan & Taiwan & 6 & 7 & 0.40 & 8 \\
\hline Warsaw & Poland & 4 & 12 & 0.29 & 9 \\
\hline Buenos Aires & Argentina & 3 & 15 & 0.18 & 10 \\
\hline Columbian & Columbia & 5 & 9 & 0.18 & 10 \\
\hline Korea & South Korea & 6 & 7 & 0.15 & 12 \\
\hline Tel Aviv & Israel & 4 & 12 & 0.04 & 13 \\
\hline Prague & Czech Republic & 3 & 15 & 0.02 & 14 \\
\hline Russian Trading System & Russia & 5 & 9 & 0.02 & 14 \\
\hline Caracas & Venezuela & 4 & 12 & 0.01 & 16 \\
\hline Santiago & Chile & 9 & 4 & 0.00 & 17 \\
\hline Mean & & 6.18 & & 0.41 & \\
\hline Median & & 5 & & 0.29 & \\
\hline \multicolumn{6}{|l|}{ Developed Markets } \\
\hline Italian & Italy & 5 & & 0.11 & \\
\hline Paris & France & 4 & & 0.05 & \\
\hline Tokyo & Japan & 9 & & 0.13 & \\
\hline
\end{tabular}

Notes: Of the 25 emerging markets that are routinely followed by the Economist, the 17 stock exchanges listed above define their mandated tick size to be a positive step function (at least three steps) of stock price. The remaining eight emerging countries (exchanges) are Brazil (Sao Paulo), China (Shenzhen), Egypt (Cairo \& Alexandria), Hungary (Budapest), India (Mumbai), Mexico (Mexican), Peru (Lima) and South Africa (Johannesburg). The median relative tick size (ratio legal tick size to price) is calculated using the mandated tick size of a stock exchange's median tick regime and its corresponding midpoint price. Ranks are in order of descending magnitude. The tick rule information was provided by the respective exchanges. For comparison, step function rules used in three developed markets are presented at the lower part of the table.

The comparison of clustering across three regime groups in the ISE, using the standardized range figures, show that the third regime group has the largest degree of clustering $(0.51$ versus 0.23 and 0.17 ) For the three regime families, the frequencies of transactions in the zero-five category are $20.58 \%, 52.71 \%$ and $11.06 \%$, respectively. Correspondingly, the frequencies of transactions with even final digits are $50.72 \%, 52.71 \%$ and $52.57 \%$. The expected frequencies for the zerofive category are $20 \%, 50 \%$ and $10 \%$ for the respective three regime families. The even digit category expected frequency is $50 \%$ for each of the three families. Chi-square tests reject the null of no clustering for each regime group for both measures. Neither measure, however, supports the presence of economically strong clustering. ${ }^{4}$

To put the extent of clustering in the ISE in better perspective, corresponding figures are calculated for five of the 17 emerging markets listed in Table 2 using the data in Brown et al. (2002). The standardized ranges for Hong Kong, Jakarta, Philippine, Singapore, and Taiwan markets are $0.53,0.70,0.71,0.66$ and 0.58 , respectively. According to this measure, the ISE has a lower degree of clustering than those other markets. Based on the total number of available final digits 
Table 3. Frequencies of the final digits, all transactions

\begin{tabular}{|c|c|c|c|}
\hline \multirow[b]{2}{*}{ Final digits } & \multicolumn{3}{|c|}{ Tick size families } \\
\hline & $10,100,1000,10000$ & $25,250,2500$ & $50,500,5000$ \\
\hline 0 & 10.58 & 27.21 & 6.22 \\
\hline 50 & & & 4.67 \\
\hline 100 & 10.26 & & 4.78 \\
\hline 150 & & & 4.06 \\
\hline 200 & 11.10 & & 4.42 \\
\hline 250 & & 24.40 & 4.01 \\
\hline 300 & 10.97 & & 4.17 \\
\hline 350 & & & 3.75 \\
\hline 400 & 10.09 & & 4.39 \\
\hline 450 & & & 4.08 \\
\hline 500 & 10.00 & 25.50 & 4.84 \\
\hline 550 & & & 4.81 \\
\hline 600 & 9.32 & & 5.55 \\
\hline 650 & & & 5.44 \\
\hline 700 & 9.20 & & 6.36 \\
\hline 750 & & 22.89 & 6.04 \\
\hline 800 & 9.62 & & 6.03 \\
\hline 850 & & & 5.25 \\
\hline 900 & 8.85 & & 5.80 \\
\hline 950 & & & 5.33 \\
\hline 0 and 5 & $\begin{array}{c}20.58 \\
(0.007)\end{array}$ & $\begin{array}{c}52.71 \\
(0.031)\end{array}$ & $\begin{array}{c}11.06 \\
(0.012)\end{array}$ \\
\hline Even & $\begin{array}{c}50.72 \\
(0.008)\end{array}$ & $\begin{array}{c}52.71 \\
(0.031)\end{array}$ & $\begin{array}{c}52.57 \\
(0.029)\end{array}$ \\
\hline Std. Range & 0.23 & 0.17 & 0.51 \\
\hline
\end{tabular}

Notes: The ISE has ten tick regimes. To facilitate analysis, these tick regimes are collapsed into three groups: (1) regimes 10, 100, 1,000, and 10,000, (2) regimes 25, 250 , and 2,500, (3) regimes 50, 500, and 5,000. The categories in the final digits column are based on representative regimes from each of these three groups. For example, the TL100 tick regime, in which the possible final digits of prices take on values between 0 and 900 in increments of 100, represents the first group. There, the 200 category includes transactions at prices with: final two digits of 20 if tick size is 10 , final three digits of 200 if tick size is 100 , final four digits of 2,000 if tick size is 1,000 , and final five digits of 20,000 if tick size is 10,000. Analogously, the final digits column uses the TL25 (TL50) tick regime as the representative regime for the second (third) group. The number of observations in these three regime groups is $2,223,859,3,011,713$, and 2,927,151, respectively. $p$-values for the chi-square tests for the null of no clustering are given in parentheses.

of prices, four of these five emerging markets are comparable to the first regime family of the ISE. The zero-five digit category frequency for the Hong Kong, Philippine, Singapore and Taiwan Stock Exchanges are $25.2 \%, 26.1 \%, 26.1 \%$ and $25.3 \%$, respectively. The respective even digit percentages are 53.0, 53.3, 53.1 and 52.7. Jakarta is comparable to the ISE's second regime family in that both Jakarta measures are identical and amount to $61.3 \%$. Thus, compared to these exchanges, the ISE displays slightly less clustering using the even digit measure and noticeably less using the zero-five digit measure.

For the remainder of this analysis, the frequency of transactions with even final digits is used to measure the extent of clustering in the ISE for two reasons. First, the even digit measure 
enables the three clustering families to be treated as a single group. Second, in the context of the price resolution explanation, this measure shows the extent of two-tick rounding, which may be an important phenomenon in a market characterized by a seemingly large relative tick size. A potential drawback of this measure, however, is that it will be biased downward for the first regime family if Goodhardt and Curcio's (1991) attraction of numbers explanation is valid. ${ }^{5}$ Therefore, as a check of robustness, all the analyses that follow are repeated by censoring the transactions made within this regime family. The results (not shown) are qualitatively same as those provided by the full sample.

The first row of Table 4 presents the distribution of the clustering variable, the fraction of even priced transactions. For each stock in the sample, this fraction is calculated on a weekly basis to facilitate the multivariate analyses in the next section. The reported distribution is obtained by pooling weekly observations of all the stocks in the sample. Mean and median figures are $52.2 \%$ and $52.3 \%$, respectively. These percentages are very similar to the ones reported above.

Clustering, according to Harris (1991), can be disaggregated into two parts. To illustrate, using the even digit measure, clustering occurs if a transaction moves a price from an even ending digit to another even ending digit. Clustering also occurs when a transaction does not produce a price change and the price in question ends in an even digit. In other words, the difference in probabilities of a price reaching an even versus an odd level characterizes the first part. The second part ignores this difference and is concerned with the length in transaction time price spends on even versus odd levels. These two parts are examined separately to assess their relative importance in overall clustering.

To examine the first part, the initial transaction plus those that lead to a change in price are considered for each stock-session. For the 28 stocks, 677,314 intraday price changes within 15,766 trading sessions result in a set of 693,080 transactions. The second row of Table 4 shows the distribution of clustering variable, the fraction of even priced transactions calculated for each

Table 4. Distribution of clustering

\begin{tabular}{cccccccc}
\hline & & & \multicolumn{5}{c}{ Quartiles } \\
\cline { 4 - 8 } & Mean & S.D. & Min & $25 \%$ & $50 \%$ & $75 \%$ & Max \\
\hline 1 & 0.522 & 0.070 & 0.190 & 0.479 & 0.523 & 0.563 & 0.778 \\
& $(0.000)$ & & & & $(0.000)$ & & \\
2 & 0.502 & 0.008 & 0.432 & 0.498 & 0.501 & 0.504 & 0.571 \\
& $(0.000)$ & & & & $(0.000)$ & & \\
3 & 1.131 & 0.335 & 0.229 & 0.916 & 1.089 & 1.271 & 3.511 \\
& $(0.000)$ & & & & $(0.000)$ & & \\
\hline
\end{tabular}

Notes: The variable in Rows 1 and 2 is the clustering measure, the frequency of transactions with even final digits. Row 1 shows the distribution when all transactions in the sample are used, while the data used to create Row 2 contain transactions that result in a change in price. The variable in Row 3 is relative price stickiness. It relies on the number of transactions within a series (a series consists of consecutive trades that occur at the same price). Weekly averages of this measure are calculated separately for even and odd series. Their ratio (even to odd) gives the tendency of transaction price spending longer time at even than odd price levels. The $t$-test (Wilcoxon Signed Rank test) is used to test that mean (median) is equal to 0.5. All three distributions are based on 1,708 observations ( 61 weeks $\times 28$ firms). These observations rely on $8,162,723$ transactions in Rows 1 and 3, and 693,080 transactions in Row 2. p-values are in parentheses, with 0.000 denoting a $p$-value of less than 0.0005 . 
stock-week. The mean and median values are 50.2\% and 50.1\%, respectively. These figures suggest that clustering associated with price changes, although highly significant at conventional statistical levels, is economically extremely small. Therefore, almost all of the clustering shown in the first row of Table 4 is associated with the tendency of price spending relatively longer time at even than odd price levels (price stickiness).

The second part of clustering is examined indirectly by measuring the tendency of transaction prices spending longer times at even than odd price levels without calculating a clustering measure. To determine this asymmetry in price stickiness, consecutive transactions at the same price (hereafter they will be referred to as a series) are considered. Each transaction series is classified as either even or odd based on the transaction price. The number of transactions within a series is used to characterize price stickiness. For each stock, weekly averages are calculated separately for even and odd series. Their ratio (even to odd) shows the tendency of transaction price spending relatively longer time at even than odd price levels. The third row of Table 4 gives, for each stock, the distribution of relative price stickiness. The mean and median are 1.13 and 1.09 , respectively. In other words, considering consecutive trades at the same price, there occur, on average, more sequential transactions when the price is even rather than odd.

As indicated above, the second part of clustering is not measured by the fraction of even priced series in the no price change data $\left(C_{p s}\right)$ but by the ratio of average even to average odd series lengths $(R)$. To better understand the rationale for this measure, consider two different ways in which overall clustering can be expressed in terms of clustering associated with price change and no price change data (see Appendix):

$$
C_{o}=\frac{R}{R+\left[\left(1-C_{p c}\right) / C_{p c}\right]}=C_{p s}+\frac{S}{T}\left(C_{p c}-C_{p s}\right)
$$

where $C_{o}$ and $C_{p c}$ denote the fractions of even priced transactions in the overall sample and in price change data, respectively. $S$ and $T$ denote total number of series and transactions in the overall sample, respectively. Thus, $R$ and $C_{p c}$ (but not $C_{p s}$ and $C_{p c}$ due to the extra term) together are sufficient to describe the overall clustering.

In summary, the findings show that it is almost equally likely that a series starts at an even or odd price (in Table 4, Row 2 mean and median values are 50.2\% and 50.1\%, respectively). Even prices, however, last relatively longer in transaction time than do odd prices (in Table 4, Row 3 mean and median values are 1.13 and 1.09 , respectively). Thus, the economically little clustering observed is associated with the asymmetry in price stickiness.

Clustering, price changes and spread sizes are interrelated and have a common dependence on relative tick size. Clustering associated with price changes is related to the frequency distribution of price changes. To observe clustering of this kind, multiple-tick price changes must occur with odd levels being skipped more frequently than even levels. The size of a price change, in turn, is related both to the size of the spread via the bid-ask bounce and to gaps in the limit order book. Clustering associated with price stickiness is also related to the frequency distribution of price changes. Price discreteness leads to stickiness because the observed price will not change (other than bid-ask bounce) until true price moves significantly closer to the next available discrete price. Clustering of this type will arise if stickiness is more prevalent at even than odd prices.

Price change and spread sizes are reported in Table 5. The first three columns of this table classify the 677,314 within-session price changes, based on the magnitude and the sign of change. Price changes by more than one tick only occur in $.03 \%$ of the possible cases (excluding close-to-open observations). ${ }^{6}$ 
Table 5. Price change and spread size frequencies

\begin{tabular}{lrrrrr}
\hline & \multicolumn{2}{c}{ Price change } & & \multicolumn{2}{c}{ Spread } \\
\cline { 2 - 3 } Size & \# Down & \multicolumn{1}{c}{ \# Up } & & Size & \# \\
\hline 1 & 336,963 & 337,900 & & 7,147 \\
2 & 958 & 968 & & 2 & 130 \\
3 & 168 & 132 & & 5 \\
4 & 66 & 53 & & 13 \\
5 & 28 & 23 & & 6 \\
6 & 18 & 16 & & \\
7 & 9 & 2 & & 1 \\
8 & 2 & 4 & & \\
10 & 1 & 0 & & \\
11 & 1 & 1 & & \\
12 & 1 & 0 & & \\
Total & 338,215 & 339,099 & Total & 7,297 \\
\hline
\end{tabular}

Notes: All categories are scaled by tick size. Price change frequencies rely on transaction data for 28 stocks. The sample period contains 15,766 stock-sessions. There are 8,162,723 transactions and 693,080 series in the data. Since the first transaction/series in each stock-session is lost in the calculation, price changes in $677,314(693,080-15,766)$ of $8,146,957(8,162,723-15,766)$ transactions. Thus, price changes in 8.31 percent of transactions $(677,314 / 8,146,957)$ and a price change of at lest two ticks is observed in 0.03 percent of transactions $(2,451 / 8,146,957)$. Spread size frequencies reflect bid and ask prices at the daily close of the market. Spread data were compiled from Dunya, a daily Turkish financial newspaper. The data were screened for instances of no reported spread, missing bid or ask quotes, and days in which systematic errors were found in the newspaper. There are 7,914 stock-days during the sample period.

The ISE data used in this study do not contain quoted prices. However, to provide some evidence regarding spread size, bid and ask quotes at the close of the second trading session are compiled from Dunya, a daily Turkish financial newspaper. The data are screened for instances of no reported spread, missing bid or ask quotes, and days in which systematic errors are found in the newspaper. The distribution of spread size is presented in columns four and five of Table 5. Overall, in 7,147 of the 7,297 observations (98\%) the size of bid-ask spread is at the minimum possible value of one tick. ${ }^{7}$ Thus, the spread size and price change distributions suggest that the ISE can be called a one-tick market. Observing one-tick price changes virtually all of the time is not surprising given the dominance of one-tick spreads in the data. A one-tick change means an even price is followed by an odd price and vice versa. This is likely to be the reason for the finding that there is little clustering associated with price changes as shown in the second row of Table 4.

\section{Nature of Clustering in the ISE}

Whether uncertainty about underlying security values explains the variation in clustering, as argued by the price resolution hypothesis, is examined next. Motivated by previous studies, e.g. Ball et al. (1985), Harris (1991), Brown et al. (1991), and Aitken et al. (1996), price volatility, average trade size (i.e. average volume per trade), trading frequency, and relative tick size are chosen as the explanatory variables in the analysis of clustering. The first three variables 
act as proxies for the stock of information in the market. Relative tick size, on the other hand, serves as a control variable because it shows the effect of mandated tick size. These prior studies find a positive (negative) association between clustering and the price volatility (other three) variable(s).

The data are arranged in time-series cross-section (TSCS) format by relying on weekly time intervals. Kmenta's (1986) method is used to pool the data. All explanatory variables are defined for each trading session. Volatility is measured by the Garman and Klass (1980) estimator, which uses opening, closing, high, and low prices per session. ${ }^{8}$ Average trade size per session is expressed in US dollars to mitigate the potential distortions caused by extremely high inflation. ${ }^{9}$ The number of total transactions per session measures trading frequency. Finally, relative tick size per session is obtained as the average of transaction-by-transaction figures. Their weekly averages are formed to match the frequency of explanatory variables with that of dependent variables. In total, there are 1,708 observations ( 61 weeks $\times 28$ firms).

The following empirical model is estimated to explain the variation in dependent variables:

$$
\begin{aligned}
Y_{i, t}= & \beta_{0}+\beta_{1} \cdot \text { Volatility }_{i, t}+\beta_{2} \cdot \text { Relative } \text { Tick }_{i, t}+\beta_{3} \cdot \text { Trade Size }_{i, t} \\
& +\beta_{4} \cdot \text { Trading Frequency } \\
i, t & +\varepsilon_{i, t}
\end{aligned}
$$

where $Y_{i, t}$ denotes either overall clustering, clustering associated with price changes, price stickiness at even and odd price levels, or relative price stickiness for stock $i$ during week $t$. The first two variables show fraction of even priced transactions, while the remaining ones are based on the number of consecutive transactions at the same price as explained in Section 3.

As first described by Parks (1967), feasible generalized least squares (FGLS) can be used to estimate Equation (2). Beck and Katz (1995), however, argue that for typical social science data, the FGLS standard errors understate the true variability of the estimated coefficients. Their Monte Carlo simulations suggest that the use of the OLS estimates with panel corrected standard errors (PCSE) gives better results for typical sample sizes. Therefore, multivariate analyses in this paper employ PCSE estimation. ${ }^{10}$

To consider the possibility of obtaining biased coefficient estimates if the assumption of a common intercept fails, the Hausman (1978) test is used, as suggested by Green et al. (2001). Under the null hypothesis that intercepts are uncorrelated with the other regressors, pooled regression, where a common intercept term is assumed for all cross-sectional units, produces unbiased estimates. These estimates are more efficient than those produced by least squares dummy variables (LSDV) estimation. If the hypothesis is not true, then the former estimates will be biased while LSDV estimates will still be unbiased. Therefore, in each instance, the specification chosen is based on the Hausman (1978) test.

The nature of clustering for the whole sample is examined first. The first row of Table 6 reports the relevant estimation results. None of the coefficients are significant, indicating that overall clustering is not sensitive to the level of uncertainty on the ISE.

The results for clustering associated with price changes are presented in the second row of Table 6. This type of clustering increases with volatility and falls with both proxies of trading activity. The coefficient of the relative tick size is significantly negative showing that even the limited variation in this variable is important. The negative relationship means that an increase in relative tick size decreases the chance of observing multiple tick price changes. With one-tick price changes an even price follows an odd price and vice versa, not giving rise to any clustering associated with price changes. These findings are consistent with the price resolution explanation and similar findings are reported in prior studies that examine the nature of overall clustering 
Table 6. Relation between uncertainty and clustering

\begin{tabular}{|c|c|c|c|c|c|c|c|c|c|c|c|}
\hline & Intercept & Volatility & $\begin{array}{l}\text { Trade size } \\
\left(\times 10^{-5}\right)\end{array}$ & $\begin{array}{l}\text { Trading freq. } \\
\left(\times 10^{-5}\right)\end{array}$ & Relative tick & Wald & $R$ sq. & Hausman & DW & Heteroscedasticity & $\begin{array}{l}\text { Cross-sectional } \\
\text { correlation }\end{array}$ \\
\hline 1 & $\begin{array}{l}0.52931 \\
(0.000)\end{array}$ & $\begin{array}{c}-3.62321 \\
(0.256)\end{array}$ & $\begin{array}{c}-0.08910 \\
(0.144)\end{array}$ & $\begin{array}{l}0.24700 \\
(0.509)\end{array}$ & $\begin{array}{c}-0.03863 \\
(0.946)\end{array}$ & $\begin{array}{l}2.98 \\
(0.562)\end{array}$ & 0.002 & $\begin{array}{l}2.69 \\
(0.260)\end{array}$ & 1.920 & $\begin{array}{c}38.610 \\
(0.087)\end{array}$ & $\begin{array}{r}499.852 \\
(0.000)\end{array}$ \\
\hline 2 & $\begin{array}{l}0.50568 \\
(0.000)\end{array}$ & $\begin{array}{l}1.83180 \\
(0.000)\end{array}$ & $\begin{array}{c}-0.02030 \\
(0.005)\end{array}$ & $\begin{array}{c}-0.20200 \\
(0.000)\end{array}$ & $\begin{array}{c}-0.29349 \\
(0.000)\end{array}$ & $\begin{array}{c}155.04 \\
(0.000)\end{array}$ & 0.049 & $\begin{array}{c}131.26 \\
(0.000)\end{array}$ & 1.954 & $\begin{array}{c}15,181.23 \\
(0.000)\end{array}$ & $\begin{array}{c}496.576 \\
(0.000)\end{array}$ \\
\hline 3 & $\begin{array}{l}6.77285 \\
(0.000)\end{array}$ & $\begin{array}{c}-1073.66400 \\
(0.000)\end{array}$ & $\begin{array}{l}13.57000 \\
(0.017)\end{array}$ & $\begin{array}{c}411.08000 \\
(0.000)\end{array}$ & $\begin{array}{c}158.31290 \\
(0.000)\end{array}$ & $\begin{array}{c}384.82 \\
(0.000)\end{array}$ & 0.906 & $\begin{array}{l}24.76 \\
(0.000)\end{array}$ & 1.417 & $\begin{array}{c}88.284 \\
(0.000)\end{array}$ & $\begin{array}{c}1,537.334 \\
(0.000)\end{array}$ \\
\hline 4 & $\begin{array}{l}6.03036 \\
(0.000)\end{array}$ & $\begin{array}{c}-628.48970 \\
(0.007)\end{array}$ & $\begin{array}{l}16.39000 \\
(0.004)\end{array}$ & $\begin{array}{c}338.05000 \\
(0.000)\end{array}$ & $\begin{array}{c}164.32130 \\
(0.000)\end{array}$ & $\begin{array}{l}445.80 \\
(0.000)\end{array}$ & 0.888 & $\begin{array}{l}11.40 \\
(0.003)\end{array}$ & 1.319 & $\begin{array}{r}129.588 \\
(0.000)\end{array}$ & $\begin{array}{r}2,008.822 \\
(0.000)\end{array}$ \\
\hline 5 & $\begin{array}{l}1.10949 \\
(0.000)\end{array}$ & $\begin{array}{c}-49.98666 \\
(0.002)\end{array}$ & $\begin{array}{c}-0.34000 \\
(0.260)\end{array}$ & $\begin{array}{l}1.77000 \\
(0.318)\end{array}$ & $\begin{array}{l}5.12746 \\
(0.066)\end{array}$ & $\begin{array}{l}10.98 \\
(0.027)\end{array}$ & 0.008 & $\begin{array}{l}2.35 \\
(0.308)\end{array}$ & 1.937 & $\begin{array}{l}66.988 \\
(0.000)\end{array}$ & $\begin{array}{r}597.220 \\
(0.000)\end{array}$ \\
\hline
\end{tabular}

Notes: The dependent variable in the first two rows is the clustering measure, the frequency of transactions with even final digits per week. Row 1 shows estimation results when all transactions in the sample are used, while the data used to create Row 2 contain transactions that result in a change in price. The dependent variable is price stickiness per week for even and odd price series in Rows 3 and 4, respectively. It relies on the number of transactions within a series (a series consists of consecutive trades that occur at the same price. The dependent variable in Row 5 is relative price stickiness per week. Weekly averages of price stickiness measure are calculated separately for even and odd series. Their ratio (even to odd) gives the tendency of transaction price spending longer time at even than odd price levels. All estimations use 1708 observations (61 weeks $\times 28$ firms). These observations are based on 8,162,723 transactions in Row 1, and 693,080 series in Rows 2-5. Wald statistic tests the hypothesis that all coefficients excluding the constant are zero. Based on the Hausman (1978) test, the results reported in each row is obtained from either Least squares dummy variables (separate intercept term for each firm) or pooled OLS (common intercept term) estimation both with panel corrected standard errors. For least squares dummy variables estimations, dummy variable coefficient estimates are not reported. The last three columns show tests used in choosing the form of the error covariance matrix. The Durbin-Watson statistic, DW, (adjusted for transitions between successive stock time-series) is used to test for the existence of first order serial correlation. The Wald and Lagrange Multiplier (LM) statistics are used to test for heteroskedasticity and cross-sectional correlation, respectively. Under the null, Hausman, Wald, and LM are distributed as $\chi^{2}(2), \chi^{2}(28)$ and $\chi^{2}(378)$, respectively. The lower and upper five percent critical values for DW $\left(k^{\prime}=4\right)$ are 1.728 and 1.810 , respectively. Where appropriate, $p$-values are provided in parentheses, with 0.000 denoting a $p$-value of less than 0.0005 . 
such as Harris (1991), Aitken et al. (1996), Hameed and Terry (1998), and Booth et al. (2000). This evidence indicates that, although it is typically negligible, clustering associated with price changes rises when the level of uncertainty in the market goes up considerably.

Rows 3 and 4 of Table 6 report regression estimates for price stickiness at even and odd price levels, respectively. All of the coefficients are significant in both estimations. Their signs show that, as expected, price stickiness is negatively related to uncertainty. The positive coefficient of relative tick size implies that for a given level of uncertainty, the larger the relative tick size the less likely is a change in price leading to larger price stickiness. To analyse the variation in clustering associated with no price change data, relative price stickiness is used as the dependent variable. The fifth row of Table 6 shows that only the coefficient estimate of volatility is significant. Its negative sign indicates that relative price stickiness decreases during volatile weeks. Thus, the relationship between clustering and volatility depends on the type of clustering being considered.

As previously discussed, clustering, price changes and spread sizes are interrelated. Therefore, to complement the analysis of the nature of clustering, variation in price changes and spread sizes is examined. The hypothesis is that those rare cases of observing multiple tick spreads and price changes, shown in the previous section, are associated with periods in which uncertainty in the market increases.

There is an overlap in determinants of clustering and relative spreads, even though the same variable may proxy a different factor depending on the context in which it is used. Empirical models, such as those devised by McInish and Wood (1992) and Harris (1994), employ measures of trading activity, risk of the security, information asymmetry, and the extent of competition among market makers as determinants of relative bid-ask spreads. In addition, price level is used as control variable. Thus, the four variables that have been used so far in this paper are also used to explain variation in relative spread. The two measures of trading activity are expected to have negative coefficients because increase in trading activity leads to economies of scale in trading costs. Price volatility is predicted to have positive coefficient to compensate risk-averse market makers for their suboptimal portfolio position. Finally, relative tick size (instead of price) is used to control for the effect of price discreteness and is expected to have positive coefficient.

Links have been documented between price changes and spreads, e.g. via the bid-ask bounce or their common dependence on information asymmetry in the market (Hasbrouck, 1991). By relying on such links, for example, Hausman et al. (1992) include lagged spread in their estimation of conditional distribution of transaction price changes. Based on the same reasoning, the same set of variables is used to explain variation in price change magnitudes. The assumed positive relation between the price change and spread size implies that the coefficient estimates will have identical signs in both estimations.

The fraction of spreads and price changes that exceed the tick size are used as dependent variables in testing the hypothesized positive relation of spread and price change magnitudes to uncertainty. Table 7 reports the PCSE estimation results. In Rows 1 and 2, the dependent variables are the fractions of multiple-tick spread and price change observations, respectively. In Row 1, the coefficients of volatility, relative tick, and trading frequency are statistically significant and have predicted signs. ${ }^{11}$ Along with these three variables, average trade size is significant in Row 2. Rows 3 and 4 of the table repeat the estimation in the second row separately for initial prices at even and odd levels, respectively. For both estimations, all the coefficients are significant and have predicted signs. Thus, the evidence in this table supports the hypothesis that although the ISE is typically a one tick market, multiple tick price changes and spreads are observed when uncertainty about underlying security values increases. 
Table 7. Relation between uncertainty and the magnitudes of spread and price change

\begin{tabular}{|c|c|c|c|c|c|c|c|c|c|c|c|}
\hline & Intercept & Volatility & $\begin{array}{l}\text { Trade size } \\
\left(\times 10^{-5}\right)\end{array}$ & $\begin{array}{l}\text { Trading freq. } \\
\left(\times 10^{-5}\right)\end{array}$ & Relative tick & Wald & $R$ sq. & Hausman & DW & Heteroscedasticity & $\begin{array}{l}\text { Cross-sectional } \\
\text { correlation }\end{array}$ \\
\hline 1 & $\begin{array}{l}0.07246 \\
(0.000)\end{array}$ & $\begin{array}{l}25.26223 \\
(0.000)\end{array}$ & $\begin{array}{c}-0.10900 \\
(0.067)\end{array}$ & $\begin{array}{c}-3.33000 \\
(0.000)\end{array}$ & $\begin{array}{c}-3.12406 \\
(0.004)\end{array}$ & $\begin{array}{l}39.11 \\
(0.000)\end{array}$ & 0.030 & $\begin{array}{l}1.66 \\
(0.436)\end{array}$ & 1.796 & $\begin{array}{r}832,710.800 \\
(0.000)\end{array}$ & $\begin{array}{r}500.188 \\
(0.000)\end{array}$ \\
\hline 2 & $\begin{array}{l}0.01751 \\
(0.000)\end{array}$ & $\begin{array}{l}8.06338 \\
(0.000)\end{array}$ & $\begin{array}{c}-0.02710 \\
(0.000)\end{array}$ & $\begin{array}{c}-0.80300 \\
(0.000)\end{array}$ & $\begin{array}{c}-0.97807 \\
(0.000)\end{array}$ & $\begin{array}{l}253.65 \\
(0.000)\end{array}$ & 0.272 & $\begin{array}{c}-1.29 \\
-\end{array}$ & 1.504 & $\begin{array}{r}23,223.770 \\
(0.000)\end{array}$ & $\begin{array}{r}1,077.030 \\
(0.000)\end{array}$ \\
\hline 3 & $\begin{array}{l}0.01258 \\
(0.000)\end{array}$ & $\begin{array}{l}5.77960 \\
(0.000)\end{array}$ & $\begin{array}{c}-0.01990 \\
(0.001)\end{array}$ & $\begin{array}{c}-0.59000 \\
(0.000)\end{array}$ & $\begin{array}{c}-0.69873 \\
(0.000)\end{array}$ & $\begin{array}{l}216.50 \\
(0.000)\end{array}$ & 0.199 & $\begin{array}{c}-2.16 \\
-\end{array}$ & 1.550 & $\begin{array}{r}55,658.260 \\
(0.000)\end{array}$ & $\begin{array}{r}914.032 \\
(0.000)\end{array}$ \\
\hline 4 & $\begin{array}{l}0.00485 \\
(0.000)\end{array}$ & $\begin{array}{l}2.29328 \\
(0.000)\end{array}$ & $\begin{array}{c}-0.00686 \\
(0.010)\end{array}$ & $\begin{array}{c}-0.21700 \\
(0.000)\end{array}$ & $\begin{array}{c}-0.27469 \\
(0.000)\end{array}$ & $\begin{array}{l}180.50 \\
(0.000)\end{array}$ & 0.231 & $\begin{array}{l}4.21 \\
(0.122)\end{array}$ & 1.646 & $\begin{array}{r}16,769.630 \\
(0.000)\end{array}$ & $\begin{array}{r}838.360 \\
(0.000)\end{array}$ \\
\hline
\end{tabular}

Notes: The dependent variable is fraction of multiple-tick spread (price change) observations per week in Row 1 (2). The dependent variable in Rows 3 and 4 differ from that in Row 2 in that the fraction is calculated separately for initial prices at even and odd levels, respectively. Estimations in Rows $2-4$ use 1,708 observations $(61$ weeks $\times$ 28 firms). As a result of balancing, Row 1 uses 1,204 observations (43 weeks $\times 28$ firms). Wald statistic tests the hypothesis that all coefficients excluding the constant are zero. Based on the Hausman (1978) test, the results reported in each row is obtained from either Least squares dummy variables (separate intercept term for each firm) or pooled OLS (common intercept term) estimation both with panel corrected standard errors. The last three columns show tests used in choosing the form of the error covariance matrix. The Durbin-Watson statistic, DW, (adjusted for transitions between successive stock time-series) is used to test for the existence of first order serial correlation. The Wald and Lagrange Multiplier (LM) statistics are used to test for heteroskedasticity and cross-sectional correlation, respectively. Under the null, Hausman, Wald, and LM are distributed as $\chi^{2}(2), \chi^{2}(28)$ and $\chi^{2}(378)$, respectively. The lower and upper five percent critical values for DW $\left(k^{\prime}=4\right)$ are 1.728 and 1.810 , respectively. Where appropriate, $p$-values are reported in parentheses, with 0.000 denoting a $p$-value of less than 0.0005 . A negative $\chi^{2}$ statistic ( $p$-value not reported) is observed both in Rows 2 and 3 . Such a result is not an unusual outcome for the Hausman (1978) test. It may be interpreted as providing strong evidence that the null hypothesis cannot be rejected. 


\section{Conclusions}

Examination of the ISE, which is an emerging market with a comparatively large relative tick size, reveals the following: in contrast to most markets studied so far, the ISE is characterized by little if any clustering. Prices are found to be quite sticky in periods of low to medium levels of uncertainty. Some clustering associated with asymmetry in price stickiness is observed during these periods. Since spreads are typically a single tick, it is not surprising that one-tick price changes are observed very frequently. A one-tick change means an even price followed by an odd and vice versa. Thus, there is little clustering associated with price changes. As uncertainty increases, however, a change in price becomes more likely. The positive relation between clustering associated with price changes and uncertainty appears to be because of the extreme levels of uncertainty in which multiple-tick (most of them are by two-ticks) spreads and price changes are observed. Thus, the relative tick size appears to be too large given the ability of the ISE to resolve prices and the typical level of uncertainty in it.

During the last decade, reductions in mandated tick sizes have been a common practice of stock exchanges. Most of the evidence on resulting change in market quality is from North American markets. These studies uniformly report that, for actively traded stocks, spread and depth at the best quotes as well as displayed cumulative depth in the limit order book fall after a reduction in tick size. While the combined effect of these on execution quality is found to be positive for small order sizes, there is disagreement regarding the effect on large order sizes. For example, Goldstein and Kavajecz (2000) and Jones and Lipson (2001) report that liquidity demanders trading large orders are worse off. In contrast, Bacidore et al. (2003) and Chakravarty et al. (2001) find no significant change. Thus the appropriateness of reducing tick size is still an unsolved issue even for markets from which most of the empirical evidence comes.

Moreover, it is even questionable that these North American findings can be generalized to other markets. Bourghelle and Declerk (2004) report that for stocks that experienced a decrease in the tick size following Euronext Paris' adoption of a new pricing grid in 1999, execution quality does not change significantly for neither small nor large order sizes. The inconclusive empirical evidence in the literature and the possibility that effect of reduction in tick size on market quality might depend on the characteristics of the market may explain the apparent reluctance of the ISE to follow suit.

Furthermore, the following two possible concerns are likely to add to this reluctance. First, it may be conjectured that the discomfort traders might face from a fall in displayed depth, a common finding in all the markets examined so far, may be more pronounced in thinner markets such as the ISE. Second, ISE policymakers may be concerned about the potential resistance from the brokerage industry. The experience of another emerging market illustrates this point. In 1994, the Hong Kong Stock Exchange reduced mandated tick sizes by 50\%. As described by Chan and Hwang (1998), trading volume dropped noticeably immediately after the reduction. The authors indicate that ' $(\mathrm{t})$ here were reports in the popular press that brokers purposely cut back trading among themselves to affect the total volume during the evaluation period'. Nevertheless, whatever the true motive of the ISE policymakers is, the analyses in this paper suggest that the tick rule in this market may not be optimal in the Grossman et al. (1997) sense.

\section{Appendix}

In this appendix, two different ways in which overall clustering can be expressed in terms of clustering associated with price change and no price change data are shown. The number of trades 
at even and odd price levels is indicated by $T_{e}$ and $T_{o}$, respectively. Similarly, $S_{e}$ and $S_{o}$ denote the number of even and odd priced series, respectively. The total number of trades (series) in the sample is signified by $T(S)$.

Define clustering associated with price change $\left(C_{p c}\right)$ and no price change $\left(C_{p s}\right)$ data as follows:

$$
C_{p c}=\frac{S_{e}}{S_{e}+S_{o}}
$$

and

$$
C_{p s}=\frac{T_{e}-S_{e}}{T-S}
$$

where $C_{p c}$ shows the fraction of series that are even and $C_{p s}$ shows the fraction of even priced transactions in no price change data. After substituting (A.1) into (A.2) and rearranging, overall clustering can be expressed in terms of $C_{p c}$ and $C_{p s}$ as:

$$
C_{o}=\frac{T_{e}}{T}=\left(1-\frac{S}{T}\right) C_{p s}+\frac{S}{T} C_{p c}=C_{p s}+\frac{S}{T}\left(C_{p c}-C_{p s}\right)
$$

Therefore, the measures for the two parts of clustering are not sufficient to describe the overall clustering due to the extra term, $S / T$.

To overcome this problem, another measure can be used instead of $C_{p s}$ :

$$
R=\frac{T_{e} / S_{e}}{T_{o} / S_{o}}
$$

which is the ratio of average even to average odd series lengths. Thus, $R$ shows the tendency of transaction price spending longer time at even than odd price levels and, therefore, is expressed in a different unit than $C_{o}$ and $C_{p c}$. Using this second measure, the overall clustering can be expressed as:

$$
C_{o}=\frac{S_{e}\left(T_{e} / S_{e}\right)}{S_{e}\left(T_{e} / S_{e}\right)+S_{o}\left(T_{o} / S_{o}\right)}=\frac{R}{R+\left[\left(1-C_{p c}\right) / C_{p c}\right]} .
$$

\section{Notes}

1 ISE stocks resemble the penny stocks in US markets. Harris (1994) interprets the high occurrence of one-tick spreads of penny stocks as evidence that tick size limits the minimum spread that can be quoted.

2 For the WAP to represent the price in a typical trade, prices corresponding to odd lot and large (special) orders are filtered in its calculation. The small to medium size round orders used in the WAP calculation are called normal orders. These have four subcategories. Since the subcategories of normal orders are not subject to a single maximum trade size limit, it is not always possible to determine whether a medium to large size trade is a special or normal order. This feature poses a problem in WAP calculation because the ISE data do not contain an identifier for order type. Nevertheless, there are only 76 ambiguous cases (out of 8,162,723 transactions). To handle these cases, two procedures are used. First, price changes during a trading session are compared to tick sizes found by treating these gray cases as normal (special) orders. Second, hand-collected WAP data from daily newspapers are compared to the calculated WAP figures.

3 Access to ISE transaction data is still limited and quote data are not available. Papers that use high frequency Turkish data employ either intraday index data for relatively longer time periods (e.g. three-year period in Bildik (2001)) or individual stock data for limited time periods (e.g. one stock and three-month period in Ekinci (2003)). The data set used in this study is currently the most comprehensive and was constructed especially for the authors. 
4 The observed prices depend on the initial price level, and for a stock with infrequent price change it may be the case that only part of the entire tick regime will be swept over time. To take this serial dependence into consideration, the adjustment discussed in Harris (1991) is used. Adjusted frequencies (not reported) are qualitatively not different than unadjusted frequencies.

5 The 'Attraction of Numbers Hypothesis' is an alternative explanation for clustering anomaly. The hypothesis predicts that the extent of clustering is highest at the final digit of 0 , followed in order by 5 , other remaining even numbers, and other remaining odd numbers.

6 In contrast, this figure is $2.6 \%$ for the NYSE during 1998 (NYSE Fact Book: 1998 Data). This is 86 times the frequency for the ISE.

7 Similar findings have been reported for low-priced stocks on the NYSE and AMEX, where the fraction of one-tick spreads falls with stock price, as documented by Harris (1994).

8 The Garman and Klass (1980) estimator is defined as: $0.5\left(\ln P_{\text {high }}-\ln P_{\text {low }}\right)^{2}-0.386\left(\ln P_{\text {close }}-\ln P_{\text {open }}\right)^{2}$, where $P_{\text {high }}, P_{\text {low }}, P_{\text {close }}, P_{\text {open }}$ are highest, lowest, closing and opening prices per session, respectively. Use of this measure avoids the noise often contained in transactions data.

9 Consumer Price Index (CPI) rose by 71.2\% during the 14-month sample period. This is not unusual for Turkey. During the 10 years preceding the sample period, average annual increase in CPI has been 76.8 percent.

10 In choosing the form of the error covariance matrix, the following procedure is used. Wald and Lagrange Multiplier tests are used to decide on the existence of panel heteroscedasticity and cross-sectional correlation, respectively. See Greene (1993, pp. 448-55). Following Beck and Katz (1995), when necessary, a correction for serial correlation is done by estimating a common autocorrelation coefficient. The Durbin-Watson statistic adjusted for transitions between successive stock time-series is used to test for the existence of first order serial correlation.

11 Noting the low R-squared value of the OLS estimation, fixed effects logit for panel data estimation is employed after transforming the dependent variable into binary one. Logit results are qualitatively the same than OLS results regarding both the sign and significance of coefficient estimates and the level of R-squared statistic.

\section{References}

Aitken, M., Brown, P., Buckland, C., Izan, H. Y. and Walter, T. (1996) Price clustering on the Australian Stock Exchange, Pacific-Basin Finance Journal, 4, pp. 297-314.

Angel, J. J. (1997) Tick size, share prices, and stock splits, Journal of Finance, 52, pp. 655-681.

Bacidore, J., Battalio, R. H. and Jennings, R. H. (2003) Order submission strategies, liquidity supply, and trading in pennies on the New York Stock Exchange, Journal of Financial Markets, 6, pp. 337-362.

Ball, C., Torous, W. and Tschoegl, A. (1985) The degree of price resolution: The case of the gold market, Journal of Futures Markets, 5, pp. 29-43.

Beck, N. and Katz, J. N. (1995) What to do (and not to do) with time-series cross-section data, American Political Science Review, 89, pp. 634-647.

Bildik, R. (2001) Intra-day seasonalities on stock returns: evidence from the Turkish Stock Market, Emerging Markets Review, 2, pp. 387-417.

Booth, G. G., Kallunki, J.P., Lin, J.C. and Martikainen, T. (2000) Internalization and stock price clustering: Finnish evidence, Journal of International Money and Finance, 19, pp. 737-751.

Bourghelle, D. and Declerk, F. (2004) Why markets should not necessarily reduce the tick size, Journal of Banking and Finance, 28, pp. 373-398.

Brown, P., Chua, A. and Mitchell, J. (2002) The influence of cultural factors on price clustering: evidence from Asia-Pacific stock markets, Pacific-Basin Finance Journal, 10, pp. 307-332.

Brown, S., Laux, P. and Schachter, B. (1991) On the existence of an optimal tick size, Review of Futures Markets, 10, pp. 50-72.

Chakravarty, S., Harris, S. P. and Wood, R. A. (2001) Decimal trading and market impact, Purdue University, Working Paper.

Chan, K. C. and Hwang, C. Y. (1998) The impact of tick size on market quality: An empirical investigation of the stock exchange of Hong Kong, Hong Kong University of Science and Technology, Working Paper.

Ekinci, C. (2003) A statistical analysis of intraday liquidity, returns and volatility of an individual stock from the Istanbul Stock Exchange, Aix-Marseille III University, Working Paper.

Garman, M. and Klass, M. J. (1980) On the estimation of security price volatilities from historical data, Journal of Business, 53, pp. 67-78. 


\section{G. G. Booth \& A. Yüksel}

Goldstein, M. and Kavajecz, K. (2000) Eighth, sixteenths, and market depth: changes in tick size provision on the NYSE, Journal of Financial Economics, 56, pp. 125-149.

Goodhardt, C. and Curcio, R. (1991) The clustering of bid/ask prices and the spread in the foreign exchange market, London School of Economics, Discussion Paper 110.

Green, D. P., Kim, S. Y. and Yoon, D. H. (2001) Dirty pool, International Organization, 55, pp. 441-468.

Greene, W. H. (1993) Econometric Analysis (New York: Macmillan).

Grossman, S., Miller, M., Cone, K. and Fischel, D. (1997) Clustering and competition in asset markets, Journal of Law and Economics, 40, pp. 23-60.

Hameed, A. and Terry, E. (1998) The effect of tick size on price clustering and trading volume, Journal of Business Finance and Accounting, 25, pp. 849-867.

Harris, L. (1991) Stock Price clustering and discreteness, Review of Financial Studies, 4, pp. 389-415.

Harris, L. (1994) Minimum price variations, discrete bid ask spreads, and quotation sizes, Review of Financial Studies, 7 , pp. 149-178.

Hasbrouck, J. (1991) Measuring the information content of stock trades, Journal of Finance, 46, pp. 179-207.

Hausman, J. A. (1978) Specification tests in econometrics, Econometrica, 46, pp. 1251-1271.

Hausman, J. A., Lo, A. W. and MacKinlay, A. C. (1992) An ordered probit analysis of transaction stock prices, Journal of Financial Economics, 31, pp. 319-379.

Kmenta, J. (1986) Elements of Econometrics (New York: Macmillan).

Jones, C. and Lipson, M. (2001) Sixteenths: direct evidence on institutional trading costs, Journal of Financial Economics, 59, pp. 253-278.

McInish, T. H. and Wood, R. A. (1992) An analysis of intraday patterns in bid/ask spreads for NYSE stocks, Journal of Finance, 47, pp. 753-764.

New York Stock Exchange Fact Book: 1998 Data (1999) (New York: New York Stock Exchange).

Parks, R. (1967) Efficient estimation of a system of regression equations when disturbances are both serially and contemporaneously correlated, Journal of the American Statistical Association, 62, pp. 500-509. 